\title{
Prohibitins and Ras2 protein cooperate in the maintenance of mitochondrial function during yeast aging ${ }^{*}$
}

\author{
Paul A. Kirchman`, Michael V. Miceli, Roger L. West, James C. Jiang, \\ Sangkyu Kim and S. Michal Jazwinski ${ }^{\bowtie}$ \\ Department of Biochemistry and Molecular Biology and Center on Aging, Louisiana State \\ University Health Sciences Center, New Orleans, Louisiana 70112 U.S.A.
}

Received: 20 August, 2003; revised: 26 September, 2003; accepted: 20 November, 2003

Key words: longevity, retrograde response, ROS, mitochondrial biogenesis, Saccharomyces cerevisiae

\begin{abstract}
The yeast Saccharomyces cerevisiae has a finite replicative life span. Yeasts possess two prohibitins, Phb1p and Phb2p, in similarity to mammalian cells. These proteins are located in the inner mitochondrial membrane, where they are involved in the processing of newly-synthesized membrane proteins. We demonstrate that the elimination of one or both of the prohibitin genes in yeast markedly diminished the replicative life span of cells that lack fully-functional mitochondria, while having no effect on cells with functioning mitochondria. This deleterious effect was suppressed by the deletion of the RAS2 gene. The expression of PHB1 and PHB2 declined gradually up to 5-fold during the life span. Cells in which PHB1 was deleted in conjunction with the absence of a mitochondrial genome displayed remarkable changes in mitochondrial morphology, distribution, and inheritance. This loss of mitochondrial integrity was not seen in cells devoid of $P H B 1$ but possessing an intact mitochondrial genome. In a subset of the cells, the changes in mitochondrial integrity were associated with increased production of reactive oxygen species, which co-localized with the altered mitochondria. The mitochondrial deficits described above were all suppressed by deletion of RAS2. Our data, together with published information, are interpreted to provide a unified view of the role of the prohibitins in yeast aging. This model posits that the key initiating event is a decline in mitochon-
\end{abstract}

\footnotetext{
$\boldsymbol{\Phi}_{\text {This work was supported by grants from the National Institute on Aging of the National Institutes of }}$ Health (U.S.P.H.S.) and from the Glenn Foundation for Medical Research to S.M.J. P.A.K. was supported by a postdoctoral fellowship from the National Institute on Aging.

- Present address: Department of Biology, Harriet L. Wilkes Honors College, Florida Atlantic University, Jupiter, FL 33558, U.S.A.

${ }^{\square}$ Correspondence to: Dr. S. Michal Jazwinski, Department of Biochemistry and Molecular Biology, Louisiana State University Health Sciences Center, 1901 Perdido St., Box P7-2, New Orleans, LA 70112 U.S.A.; phone/fax: 504568 4725; e-mail: sjazwi@lsuhsc.edu
}

Abbreviations: $\mathrm{H}_{2}$ DCFDA, 2',7'-dichlorodihydrofluorescein diacetate. 
drial function, which leads to progressive oxidative damage that is exacerbated in the absence of the prohibitins. This aggravation of the initial damage is ameliorated by the suppression of the production of mitochondrial proteins in the absence of Ras2p signaling of mitochondrial biogenesis.

Normal human diploid fibroblasts exhibit a limited proliferation potential in culture, which has been taken as a sign of senescence at the cellular level (Hayflick, 1965). The senescent phenotype of these cells, thus defined, is a dominant trait (reviewed in Smith \& Pereira-Smith, 1996), which prompted the search for a senescence factor in the form of antiproliferative mRNAs whose accumulation during the course of progressive population doublings leads to the arrest of cell division (Lumpkin et al., 1986). One such mRNA species was cloned by hybrid selection from normal liver and shown to have antiproliferative activity when injected into fibroblasts (McClung et al., 1989). The full-length clone encodes a $32-\mathrm{kDa}$ intracellular protein called prohibitin, which is ubiquitously expressed and evolutionarily conserved (Nuell et al., 1991). Synthetic prohibitin mRNA blocks DNA synthesis, when injected into normal or cancer cells. This activity has subsequently been shown to reside in the 3 '-untranslated region of prohibitin mRNA (Jupe et al., 1996).

The human prohibitin gene maps to chromosome $17 \mathrm{q} 21$ close to $B R C A 1$, and somatic mutations in the gene were found in sporadic breast cancer (Sato et al., 1992). These findings were consistent with a postulated role for prohibitin as a tumor suppressor. This notion was further supported by the report that prohibitin interacts with $\mathrm{Rb}$ and regulates the activity of the $\mathrm{Rb}$ partner $\mathrm{E} 2 \mathrm{~F}$, which is essential for the transcriptional activation of cell cycle genes (Wang et al., 1999). However, prohibitin appears to be expressed in a variety of tumor cell lines and tissues, which appears to be due to the presence of Myc binding sites in the promoter (Terashima et al., 1994; Coates et al., 2001). In addition, the expression of prohibitin appears to decline during senescence of human cells (McClung et al., 1992; Coates et al.,
2001). These observations argue against a tumor suppressor role for prohibitin, and it is now evident that prohibitin and BRCA1 map at different loci.

The intracellular localization of prohibitin was initially determined to be at the plasma membrane. This was based on the detection of the protein in a complex with membrane bound IgM (Tershima et al., 1994). In addition to prohibitin (BAP32, PHB), these complexes contained a close homologue of prohibitin, called BAP37 (REA). (We call these proteins here $\mathrm{Phb1}$ and $\mathrm{Phb2}$, respectively.) Subsequent studies have localized Phb1p to mitochondria (Ikonen et al., 1995; Coates et al., 1997) in mammalian cells, in a complex with Phb2p (Coates et al., 2001).

The yeast Saccharomyces cerevisiae has homologues of prohibitin and BAP37, which are called Phb1p and Phb2p. Investigations in this organism established the subcellular localization of the two proteins in the inner mitochondrial membrane (Berger \& Yaffe, 1998). The proteins are inaccessible to trypsin in mitoplast preparations, indicating that they are oriented towards the mitochondrial matrix. Similar results have been reported using proteinase $\mathrm{K}$ digestion of mammalian mitoplasts (Coates et al., 2001), although high concentrations of trypsin appear to effect digestion of the two proteins in yeast mitoplast preparations (Steglich et al., 1999). The two prohibitins are coordinately synthesized or stabilized, such that a null mutant in one of the genes is missing both proteins. However, this regulation occurs post-transcriptionally, because the same observation is not made at the level of mRNA (Berger \& Yaffe, 1998). These findings suggest the possibility of the existence of a Phb1p-Phb2p complex, and indeed there is evidence for such a complex in yeast (Steglich et al., 1999; Nijtmans et al., 2000). Given the presence of 
such a complex, it is curious that deletion of PHB1 has a greater effect than deletion of PHB2 on the generation of petites in stationary phase (Piper \& Bringloe, 2002), raising the possibility of some separate functions for the two prohibitins.

Current insight into the biochemical function of the prohibitins comes from the finding that they stabilize newly-synthesized mitochondrial translation products (Steglich et al., 1999; Nijtmans et al., 2000). This stabilization was shown to occur through an association of the prohibitins with the mitochondrial m-AAA protease, suggesting that they play the role of a negative regulator of this enzyme, which degrades proteins as a by-product of the assembly of large membrane protein complexes (Steglich et al., 1999). In fact, the prohibitins were found to bind stabilized mitochondrial translation products, suggesting a chaperone function (Nijtmans et al., 2000). The synthetic lethality of deletions of the prohibitin genes and the m-AAA protease gene (Steglich et al., 1999) suggests that the prohibitins are not simply negative regulators of the protease and supports the chaperone function. Clearly, the prohibitins play a role in mitochondrial integrity, and they interact genetically with mitochondrial inheritance factors (Berger \& Yaffe, 1998), although the molecular basis for this is not clear at present.

Yeast cells age, and this aging process results in a limited life span of two sorts (reviewed in Jazwinski, 2002). The first is the replicative life span, which is defined by the number of divisions available to individual yeast cells. The second is called the chronological life span, whose measure is time of survival in stationary phase. The replicative life span possesses some resemblance to cellular senescence of normal human cells in culture (Jazwinski, 1990). This similarity includes the elaboration of a cytoplasmic senescence factor (Egilmez \& Jazwinski, 1989), which has been equated with dysfunctional mitochondria (Lai et al., 2002). Yeast pro- hibitins, just as their mammalian counterparts, have been reported to impinge on cellular life span.

The prohibitins have no effect on yeast chronological life span (Piper \& Bringloe, 2002). Although it is generally clear that the prohibitins are needed to maintain a normal replicative life span, there are inconsistencies in the reported effects of deletions of the PHB1 and PHB2 genes. In one study, no significant effect was observed of deletions of either of the two genes; however, the deletion of both resulted in an approx. 40\% decrease in mean life span of wild-type cells (Coates et al., 1997). In a second study, deletion of $P H B 1$ resulted in an approx. $30 \%$ reduction in mean life span, while the effects of deletion of PHB2 or of the deletion of both genes where identical and less pronounced (Berger \& Yaffe, 1998). This study also reported an approx. 30\% decrease in mean life span when PHB2 was deleted in $r h o^{-}$cells. An approx. $20 \%$ reduction was reported when both prohibitin genes were deleted, and no effect of a PHB1 deletion was seen. (Cells that have part $\left[r h o^{-}\right]$or all $\left[r h o^{0}\right]$ of their mitochondrial genome missing have partially functional mitochondria and are known as mitochondrial petites. Nuclear petites are similarly dysfunctional due to mutations in nuclear genes encoding mitochondrial components.) A third study has stated that deletion of the prohibitin genes shortened life span of wild-type cells (Piper et al., 2002). However, a statistical treatment was not provided, and an examination of the survival curves suggests that only the deletion of both genes had an effect on glucose-containing medium, while on glycerol-containing medium deletion of either or both of the genes appeared to have the same modest effect. This study also suggested that there is a slight effect of deletion of both prohibitin genes in a nuclear petite $(\operatorname{cox} 4 \Delta)$, but this claim is not substantiated by the data presented. This is also the case for the assertion that deletion of both genes caused a reduction in life span of cells grown in the pres- 
ence of the respiratory inhibitor antimycin A. The effects on replicative life span are the only functional phenotypes that have been reported for mutants in the yeast prohibitin genes.

In 1996, we summarized briefly the results of our studies of the role of prohibitin in yeast aging (Jazwinski, 1996), and we suggested that prohibitin participates in metabolic adjustments that are important for longevity (Jazwinski, 1999). The terse account presented then seems to have precipitated some attention to prohibitin and its function in yeast aging. Since then several studies have been published on yeast prohibitin, and these studies have not always been consistent nor have they always provided a coherent model of prohibitin function in yeast aging. Therefore, we detail here the results of our studies in an effort to present a unified view.

\section{MATERIALS AND METHODS}

\section{Yeast strains and growth conditions.}

The $S$. cerevisiae strains used in this study were YPK9 (MATa, ade2-101 ${ }^{\text {ochre }}$, his3- $\Delta 200$, leu2- $\Delta 1$, lys2-801 ${ }^{\text {amber }}$, trp1- $\Delta 63$, ura3-52) and its ethidium bromide-induced mitochondrial petite $\left[r h o^{0}\right.$ ] YSK365 (Kirchman et al., 1999) and X2180-1A (MATa, SUC2, mal, mel, gal2, CUP1) (Yeast Genetic Stock Center, Berkeley, California, U.S.A.). The entire coding region of $P H B 1$ and/or PHB2 was deleted from YPK9 and YSK365 by $\gamma$-deletion, using plasmids pRS404 and pRS406 (Sikorski \& Hieter, 1989). Sequences upstream and downstream of the coding regions of the genes were amplified using the polymerase chain reaction (PCR) with the introduction of suitable restriction sites for cloning the obtained fragments in reverse orientation into the multiple cloning sites of the plasmids. The plasmids were then linearized by restriction digestion between the inversely oriented yeast genomic DNA fragments and transformed into the yeast strains, using the lith- ium acetate procedure (Ito et al., 1983) without carrier DNA. The $\gamma$-deletion replaced the entire coding regions of the genes, replacing them with either the HIS3 or URA3 selectable marker. The $R A S 2$ gene was disrupted, using plasmid pRa530 to generate a null mutant marked by LEU2 for selection (Sun et al., 1994). Several deletion clones were isolated in each case; the deletions were verified by Southern analysis, and these clones were tested. The selectable markers themselves did not affect life spans in the presence of the appropriate nutrient in the medium. Cells were cultured in YPD medium ( $2 \%$ peptone, $1 \%$ yeast extract, and $2 \%$ glucose) at $30^{\circ} \mathrm{C}$ on a shaker. Solid medium contained $2 \%$ agar.

Preparation of age-synchronized yeast cells and life span analysis. The preparation of yeast cells of specific replicative ages has been described in detail (Kim et al., 1999). Briefly, virgin or zero generation cells of strain X2180-1A were isolated from stationary phase cultures by rate-zonal sedimentation in sucrose gradients. These cells were allowed to grow synchronously through two generations, and the two-generation old mother cells were isolated by rate-zonal sedimentation in sucrose gradients. These mother cells were allowed to grow synchronously for three generations, and the five-generation old mother cells were isolated as before. This procedure of synchronous growth for three generations followed by isolation of mother cells was continued until the desired age-specific cells were obtained. This procedure yields highly pure, age-synchronized cell preparations of multiple ages spanning the replicative life span.

Yeast replicative life span determination has been described in detail (Kim et al., 1999). Fresh overnight yeast cultures initiated from colonies grown from frozen stocks were spotted onto an agar plate containing YPD medium, and 30 to 40 individual cells were isolated using a Nikon Labophot microscope equipped with a $20 \mathrm{X}$ long-working distance 
objective and with a micromanipulator attachment. Cells were incubated at $30^{\circ} \mathrm{C}$ until each cell had divided. The daughter cells (virgin or zero generation cells) were used to initiate the determination, while the mother cells were discarded. With every division (generation), the daughters were micromanipulated away and discarded. The number of progeny produced by each cell until division ceased and the cell lysed or lost refractility was recorded as its life span. The Mann-Whitney test was used to assess the significance of differences in life spans. Mortality rates were calculated using the computer program MORTAL 1.0 and smoothed over an 8-generation window, as described previously (Jazwinski et al., 1998).

Northern analysis of mRNA. Total RNA was isolated from age-synchronized cell preparations by isopycnic centrifugation in cesium trifluoroacetate (Egilmez et al., 1989). The RNA ( $5 \mu \mathrm{g}$ ) was separated by electrophoresis in agarose gels in the presence of formaldehyde and blotted onto nylon membranes (Egilmez et al., 1989). The membranes were probed with a ${ }^{32} \mathrm{P}$-labeled PCR fragment that recognizes both $P H B 1$ and $P H B 2$ mRNAs. RNA loading was normalized using the transcript of the TLC1 gene, whose expression does not change during the yeast life span. Quantification of mRNA was performed using the PhosphorImager 400E (Molecular Dynamics) and ImageQuant software.

Immunofluorescence microscopy. Yeast cells were plated on solid YPD medium from frozen stocks and colonies were then picked and cultured in liquid medium to mid-logarithmic phase in YPD at $30^{\circ} \mathrm{C}$ overnight. Cells were fixed by adding $650 \mu \mathrm{l}$ of $37 \%$ formaldehyde (Calbiochem) and $650 \mu \mathrm{l}$ of $1 \mathrm{M}$ potassium phosphate ( $\mathrm{pH} 6.5$ ) to $5 \mathrm{ml}$ of yeast culture in YPD. The cells were incubated on a shaker for $2 \mathrm{~h}$ at $30^{\circ} \mathrm{C}$. They were then washed two times with $0.1 \mathrm{M}$ potassium phosphate ( $\mathrm{pH}$ 6.5) and two times with the same buffer containing 1.0 M sorbitol (KPBS). The cells were suspended in $500 \mu \mathrm{l}$ of KPBS and then $2.5 \mu \mathrm{l}$ of 2-mercaptoethanol and $15 \mu \mathrm{l}$ Zymolyase 100T (10 mg/ml, U.S. Biologicals) were added. The suspension was incubated at $30^{\circ} \mathrm{C}$ for $30 \mathrm{~min}$ to digest the cell wall. The spheroplasts were then washed two times with KPBS and suspended in 100 to $500 \mu \mathrm{l}$ of PBS $(140 \mathrm{mM} \mathrm{NaCl}, 2.6 \mathrm{mM} \mathrm{KCl}, 8.0 \mathrm{mM}$ $\mathrm{Na}_{2} \mathrm{HPO}_{4}, 1.5 \mathrm{mM} \mathrm{KH} \mathrm{PO}_{4}, 0.5 \mathrm{mM} \mathrm{MgCl}$, $\mathrm{pH}$ 7.4), according to the size of the cell pellet. The cell suspension $(100 \mu \mathrm{l})$ was deposited on a coated microscope slide (ThermoShandon Cytoslide, Shandon) using a Cytospin3 Cytocentrifuge (900 r.p.m. for $4 \mathrm{~min}$ ). The slides were immersed once in PBS and then immersed in ice-cold acetone/methanol (1:1, $\mathrm{v} / \mathrm{v}$ ) for $1 \mathrm{~min}$. The slides were briefly air-dried, and then the cells were rehydrated by immersing in PBS. The cells were blocked with PBS-BSA ( $2 \mathrm{mg}$ bovine serum albumin (BSA) $/ \mathrm{ml}$ PBS) for $30 \mathrm{~min}$ and rinsed 3 times with PBS. Porin staining was performed by incubating the slides in a 1:20 dilution of mouse anti-yeast mitochondrial outer membrane porin monoclonal antibody (Molecular Probes, A-6449) in PBS-BSA for $1 \mathrm{~h}$ at room temperature and washed 5 times with PBS. Slides were then incubated with an AlexaFluor 488-coupled secondary antibody (goat anti-mouse IgG, Molecular Probes, A-11001) at a 1:200 dilution for $2 \mathrm{~h}$ as above, rinsed 5 times and mounted in ProLong Antifade (Molecular Probes).

Micrographs were obtained using a Leica DMRXA deconvolution microscope equipped with a mercury lamp and filters for epi-fluorescence applications and Nomarski optics. Images were captured using a Sensicam QE 12-bit, cooled digital CCD system and Slidebook image processing software. Images were obtained using a $100 \mathrm{X}$ oil-immersion objective at a total magnification of 1000. The final magnification of the cells was 5200, using a digital zoom of 5.2. Images were processed as described in the legends to the figures.

Fluorescence microscopy. Cells were grown overnight to $2 \times 10^{7}$ per $\mathrm{ml}$ in YPD 
supplemented with $120 \mu \mathrm{g} / \mathrm{ml}$ adenine at $30^{\circ} \mathrm{C}$. Mitochondria were stained in living cells growing exponentially by incubation with $20 \mu \mathrm{M} 2$ ',7'-dichlorodihydrofluorescein diacetate $\left(\mathrm{H}_{2}\right.$ DCFDA, Molecular Probes) for 2 hr or with $12.5 \mu \mathrm{m} \mathrm{H}_{2}$ DCFDA for $2 \mathrm{~h}$ together with $100 \mathrm{nM}$ Mitotracker Red CMXRos (Molecular Probes) added for the final $30 \mathrm{~min}$, in the dark at $30^{\circ} \mathrm{C}$. Cells were washed once with sterile PBS, placed on a coated microscope slide, as described above, and immediately analyzed using the Leica DMRXA microscope with a 100X objective, as described above, operating in epifluorescence mode.

\section{RESULTS}

\section{$P H B 1$ and $P H B 2$ are necessary for mainte- nance of yeast longevity}

The identification of mammalian prohibitin as an antiproliferative factor (Nuell et al., 1991) prompted us to examine the possibility that the yeast homologues PHB1 and PHB2 play a similar role. We deleted the two genes, either singly or together, in the strain YPK9 and examined the effect of these genetic manipulations on the replicative life span. As seen in Fig. 1A, there was little if any effect of deletion of the prohibitin genes on yeast life span. This indicates that $P H B 1$ and $P H B 2$ are not necessary for yeast longevity. Similar results were obtained when the $2 \%$ glucose in YPD medium was replaced by $3 \%$ glycerol (not shown), indicating that the effects of prohibitin gene deletion are not dependent on the respiratory status of the cell.

Mammalian prohibitins have been localized to the mitochondrion (Ikonen et al., 1995). Indeed, the yeast prohibitins appear to form a complex which is localized to the mitochondrial inner membrane (Berger \& Yaffe, 1998; Steglich et al., 1999; P.A. Kirchman, R.L. West, J.C. Jiang and S.M. Jazwinski, unpublished). This suggests a mitochondrial function for these proteins. Therefore, we exam- ined the effect of combining deletions of PHB1 and/or PHB2 on the life span of cells that lack fully functional mitochondria. We reasoned that there might be a synthetic effect of these deletions with mitochondrial petite mutants, which lack a mitochondrial genome $\left[r h o^{0}\right]$. Indeed, such an effect was observed (Fig. 1B). The deletion of either or both of the genes caused a marked reduction in life span. The petite mutation on its own resulted in an extension of life span, as observed previously (Kirchman et al., 1999). This life extension is caused by the induction of the retrograde response, which signals mitochondrial dysfunction resulting in changes in the expression of many nuclear genes involved in metabolism and resistance to stress (Epstein et al., 2001). The deletion of the prohibitins not only abrogated the life extension seen in the petite, but it caused a further reduction in life span. These results indicate a genetic interaction between $P H B 1$ and PHB2 and the mitochondrial genome.

The survival curves observed on deletion of the prohibitin genes in the $r h o^{0}$ strain were bimodal. There appears to be a fraction of the aging cell cohort that dies early, while the remainder of the population appears to possess a life span similar to the rho ${ }^{+}$control. The curtailment of the mean life span of the entire population of the rho ${ }^{0}$ cells harboring prohibitin gene deletions as compared to the $r h o^{0}$ control is largely due to the presence of this short-lived cohort. However, the suppression of the life extension that the rho ${ }^{0}$ cells normally enjoy also appears to contribute. An examination of the age-specific mortality rates reveals the nature of the differences between the strains (Fig. 1C). The wild-type $r h o^{+}$strain differed from the $r h o^{0}$ petite in its higher rate of aging. On the other hand, the prohibitin deletion $r h o^{0}$ strain displayed a complex mortality rate profile, with a very high mortality rate early followed by a convergence with the mortality rate of the $r h o^{0}$. The fraction of the population that died early in the three deletion strains varied somewhat from experiment to 

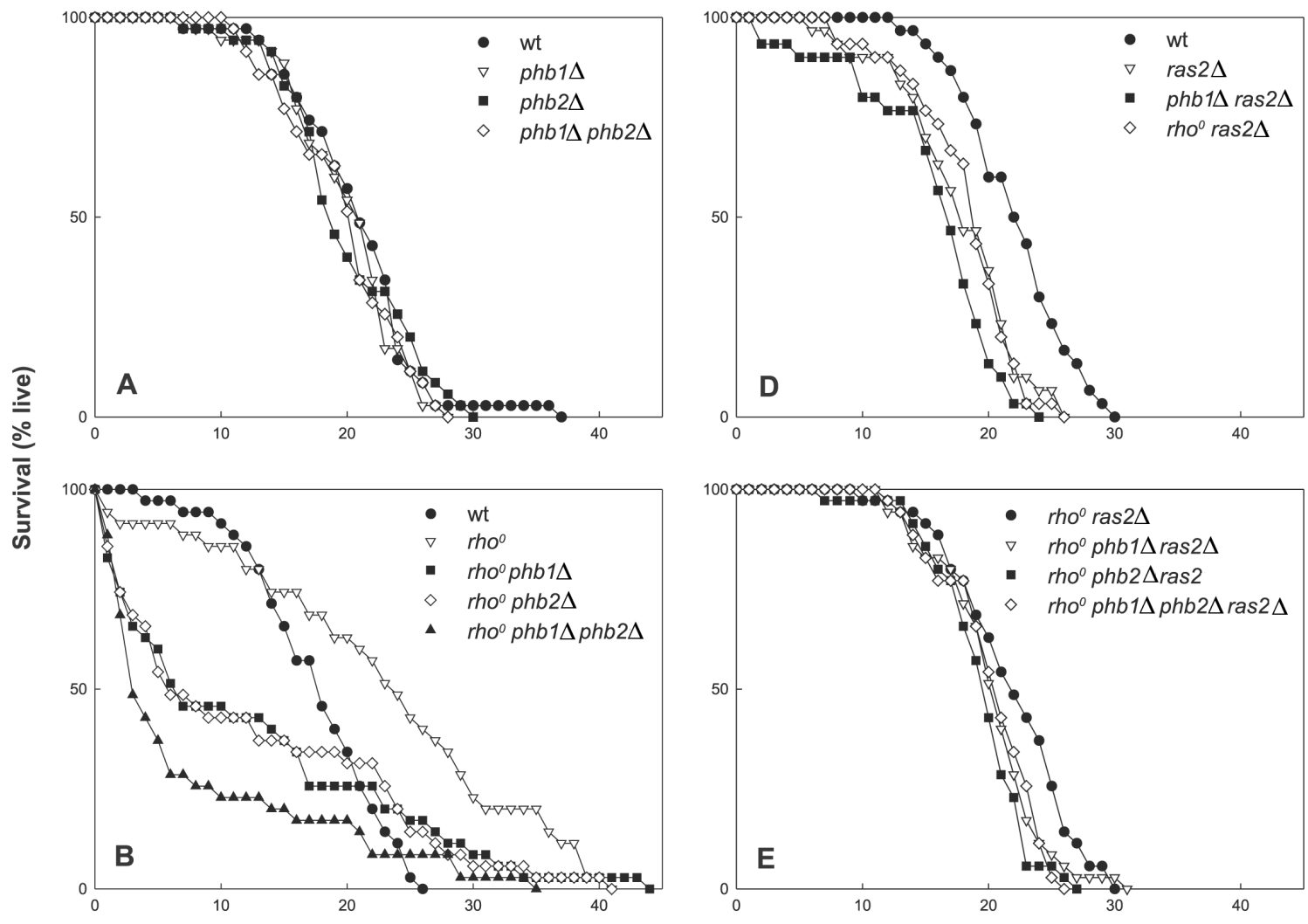

Age (generations)

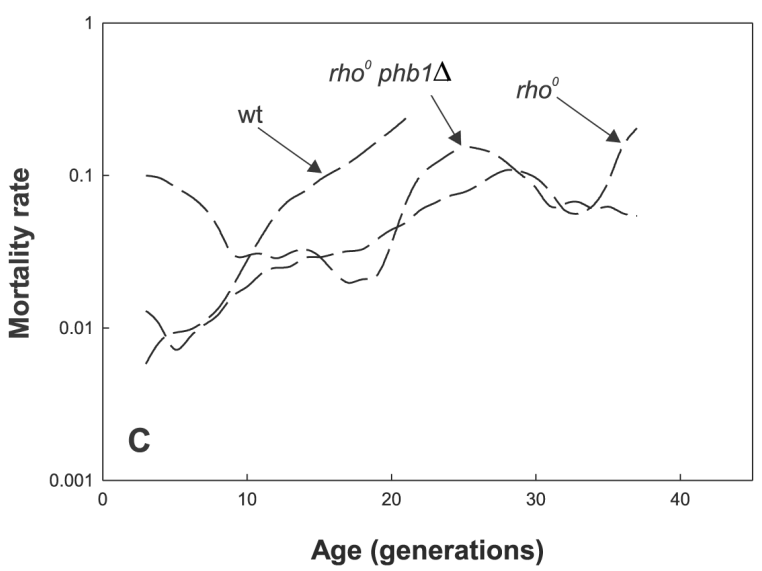

Figure 1. Effect of prohibitin gene deletion on yeast life span and the interaction with RAS2.

(A) Effect of deletion of PHB1 and/or PHB2 in wild-type (wt) cells, YPK9 [rho $\left.{ }^{+}\right]$. There were no significant differences in the life spans $(P=0.47$ to 0.97$)$. The tail in the survival curve of the wild-type is due to the presence of a petite cell, as shown previously (Kirchman et al., 1999). The mean life spans were 19.8, 19.1, 19.1, and 18.9 generations for wt, $p h b 1 \Delta, p h b 2 \Delta$, and phb1 $\Delta$ phb2 $\Delta$, respectively. (B) Effect of deletion of PHB1 and/or PHB2 in rho cells, YSK365. All the differences in life span were significant $(P=0.000002$ to 0.02$)$, except for the differences between phb1 $\Delta$ and phb2 $\Delta(P=0.96)$ and the single deletions compared to the double deletion $(P=0.13$ to 0.16$)$. However, the latter statistical analysis ignores the bimodal distribution of life spans in cells lacking prohibitin. The

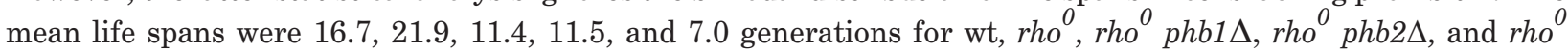
phb1 $\Delta$ phb2 $\Delta$, respectively. (C) Mortality rates (fraction of survivors that die in the next generation) as a function of age of wt, $r h o^{\circ}$, and $r h o^{0}$ phb1 $\Delta$ cells. (D) Effect of RAS2 deletion on life span. The differences in life span between wt and all the other strains were significant $(P<0.002)$. The differences between all the other strains were not significant $(P=0.05$ to 0.75$)$. The mean life spans were $21.2,16.8,14.7$, and 17.3 for wt, ras $2 \Delta, \operatorname{phb1} \Delta$ ras $2 \Delta$, and $r h o^{O}$ ras $2 \Delta$, respectively. (E) Suppression of the loss of prohibitins by deletion of $R A S 2$. The difference in life span between the $r h o^{0}$ ras $2 \Delta$ and the $r h o^{0}$ phb2 $\Delta$ ras $2 \Delta$ cells was significant $(P=0.02)$. All other differences in life span were not significant $\left(P=0.11\right.$ to 0.76 ). The mean life spans were $20.9,19.3,18.5$, and 19.3 for $r h o^{0} \operatorname{ras} 2 \Delta$, rho ${ }^{0}$ phb1 $\Delta$ ras $2 \Delta$, rho ${ }^{0}$ phb2 2 ras $2 \Delta$, and $r h o^{0}$ phb1 $\Delta$ phb2 $\Delta$ ras $2 \Delta$, respectively. 
experiment, but this fraction was smaller for the phb1 $\Delta$ and phb2 $\Delta$ strains than for the phb1 $\Delta$ phb2 $\Delta$ strain. Thus, the effects of PHB1 and PHB2 on longevity of petites were always consistent, with both genes having a similar effect as would be expected if the proteins function as a complex. The greater effect on life span of the deletion of both genes, however, suggests some differentiation in function, which is somewhat surprising given the coordinate expression of the Phb1p and Phb2p (Berger \& Yaffe, 1998). Perhaps small amounts of these proteins can play an independent role in yeast physiology.

The bimodal survival curves described above (Fig. 1B and C) may result from a heritable genetic change in a fraction of the cell population. We collected daughter cells from mothers from both phases of the survival curves; that is, we examined the progeny of mother cells that had died after only a few cell divisions and those that enjoyed many cell divisions. These progeny were used to initiate life span determinations. Cells from both phases of the survival curves generated new bimodal survival curves, which were indistinguishable from those generated by the cell cohorts from which these progeny were derived. Thus, the events resulting in the bimodal survival curves were not heritable. The development of this bimodal survival profile is, however, dependent on the loss of the mitochondrial genome, because reintroduction of fully functional mitochondria by cytoduction (Kirchman et al., 1999) completely suppressed the depression in longevity seen in the $r h o^{0}$ prohibitin deletion strains, restoring life span to that characteristic of the rho ${ }^{+}$strain (not shown).

\section{RAS2 deletion suppresses the effect of PHB1 and PHB2 deletion on the life span of petites}

Examination of the amino-acid sequence of human Phb1p reveals the presence of domains that are characteristic of Ras GTPase-activating proteins (Ras-GAPs) (Sato et al., 1992).
We have identified the same sequence motifs in yeast Phb1p. We also have found these domains in yeast Phb2p and in addition sequences found in Ras GDP/GTP- exchange factors (Ras-GEFs) and an E2F hand domain characteristic of calcium binding proteins. This suggests that the prohibitins might interact with yeast Ras2p. We therefore examined the effect of deletion of $R A S 2$ on the life span of petites in which $P H B 1$ and/or PHB2 were deleted. However, the effects of the deletion of RAS2 in several control strains were first ascertained for comparison (Fig. 1D). As seen before (Sun et al., 1994; Shama et al., 1998; Kirchman et al., 1999), deletion of RAS2 resulted in a modest decrease in life span of the $r h o^{+}$strain. The same was seen in the $r h o^{+}$ strains in which one or both of the prohibitin genes were deleted. However, the effect of $R A S 2$ deletion on the $r h o^{0}$ was more profound (compare with Fig. 1B), causing a complete suppression of the life extension normally observed. This effect has been described previously (Kirchman et al., 1999). Fig. 1E shows in contrast that deletion of RAS2 completely suppressed the life span curtailment caused by the deletion of the prohibitin genes, restoring the life span typical for a rho ${ }^{0}$ ras $2 \Delta$ strain. This latter effect is all the more remarkable because the deletion of RAS2 causes a small shortening of the life span of $\mathrm{rho}^{+}$cells (Sun et al., 1994), while completely preventing the life extension normally seen in $r h o^{0}$ cells (Kirchman et al., 1999). Thus, any negative effect of deletion of RAS2 is more than offset by the positive effect it elicits in a petite strain missing both prohibitin genes. There appears to be a complex genetic interaction between $R A S 2$, $P H B 1 / 2$, and the mitochondrial genome.

\section{PHB1/2 gene expression declines with replicative age}

The deletion of either of the prohibitin genes can have a profound effect on yeast life span. The question arises whether this has any significance for normal yeast aging. If the ex- 
pression of either of the prohibitin genes declined during the life span, this could severely affect cell survival. We therefore chose to carefully ascertain the transcript levels of PHB1 and PHB2 throughout the first one-half of the life span. By this point, cells are dying at an exponential rate, so any changes with functional implications would be apparent. As seen in Fig. 2, there was a gradual decline in PHB1/2 mRNA during the life span, such that by generation 18 the transcript content was reduced nearly 5 -fold. Such a dramatic decline may have a significant effect on the physiology of older cells, and it may contribute to their aging and ultimate demise. Recently, similar results were reported by others (Piper et al., 2002). However, only two ages of cells were examined, and the older were only 7 -generations old, making the pattern of change during the life span uncertain. Furthermore, the analysis was not quantitative. Thus, a comparison is difficult.

\section{Effect of prohibitin on mitochondrial mor- phology, distribution, and segregation}

Because the prohibitins are components of the mitochondrial inner membrane, their absence could have substantial effects on the integrity of mitochondria. We therefore examined the appearance of mitochondria in cells by fluorescence microscopy after staining the outer membrane porin. Given the dramatic effect on life span of deletion of $P H B 1$ alone in $r h o^{0}$ cells, we focused our attention on this gene. There was no effect of deletion of PHB1 in $\mathrm{rho}^{+}$cells on the appearance of the cells or of mitochondria (Fig. 3B). RAS2 deletion, either alone (Fig. 3C) or in combination with PHB1 deletion (Fig. 3D), also had no effect. All the $r h o^{+}$strains showed mainly tubular mitochondrial architecture, with daughter cells receiving their normal complement of mitochondria. In contrast, deletion of $P H B 1$ in $r h o^{0}$ cells had a dramatic effect (Fig. 4). In the $r h o^{0}$ strain, the tubular mitochondrial networks were usually less pronounced, and

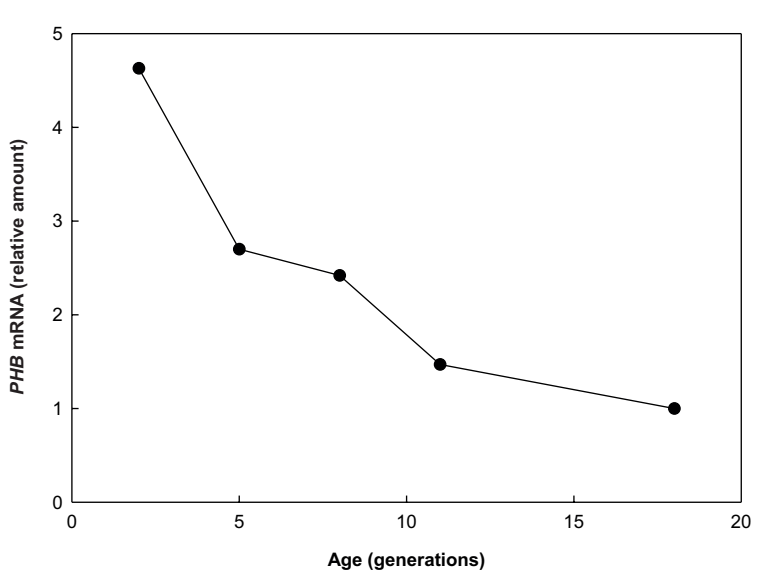

Figure 2. Expression of the prohibitin genes during the replicative life span.

Amounts of prohibitin (PHB1 plus $P H B 2$ ) mRNA are presented relative to the levels in 18-generation old cells. Similar results were obtained in two experiments.

punctate mitochondria were more frequent compared to $\mathrm{rho}^{+}$strains (Figs. $3 \mathrm{~A}$ and $4 \mathrm{~A}$ ). In the phb1 mutant, the cell morphology was altered, and the punctate mitochondrial form predominated (Fig. 4B). These punctate mitochondria had a tendency to aggregate into one or more larger structures. In many cases, daughter cells seemed to receive less mitochondrial material than normally observed (Fig. 5), and in about $2 \%$ of the cases daughters received few or no mitochondria. In some instances, mother cells lacking mitochondria were also observed. The cells that appear to inappropriately segregate mitochondria may be the cells that die early in the life span of the strain.

The deletion of RAS2 had no effect on the normal appearance of the mitochondria in rho ${ }^{0}$ cells (Fig. 4C). However, this genetic manipulation at least partially suppressed the abnormal morphology, distribution, and segregation of mitochondria observed in the presence of a deletion of $\mathrm{PHB1}$ in the $r \mathrm{o}^{\mathrm{O}}$ cells (Fig. 4D). This paralleled the suppression of the curtailed life span obtained by deletion of RAS2 (Fig. 1E). This result provides further support for an interaction between 

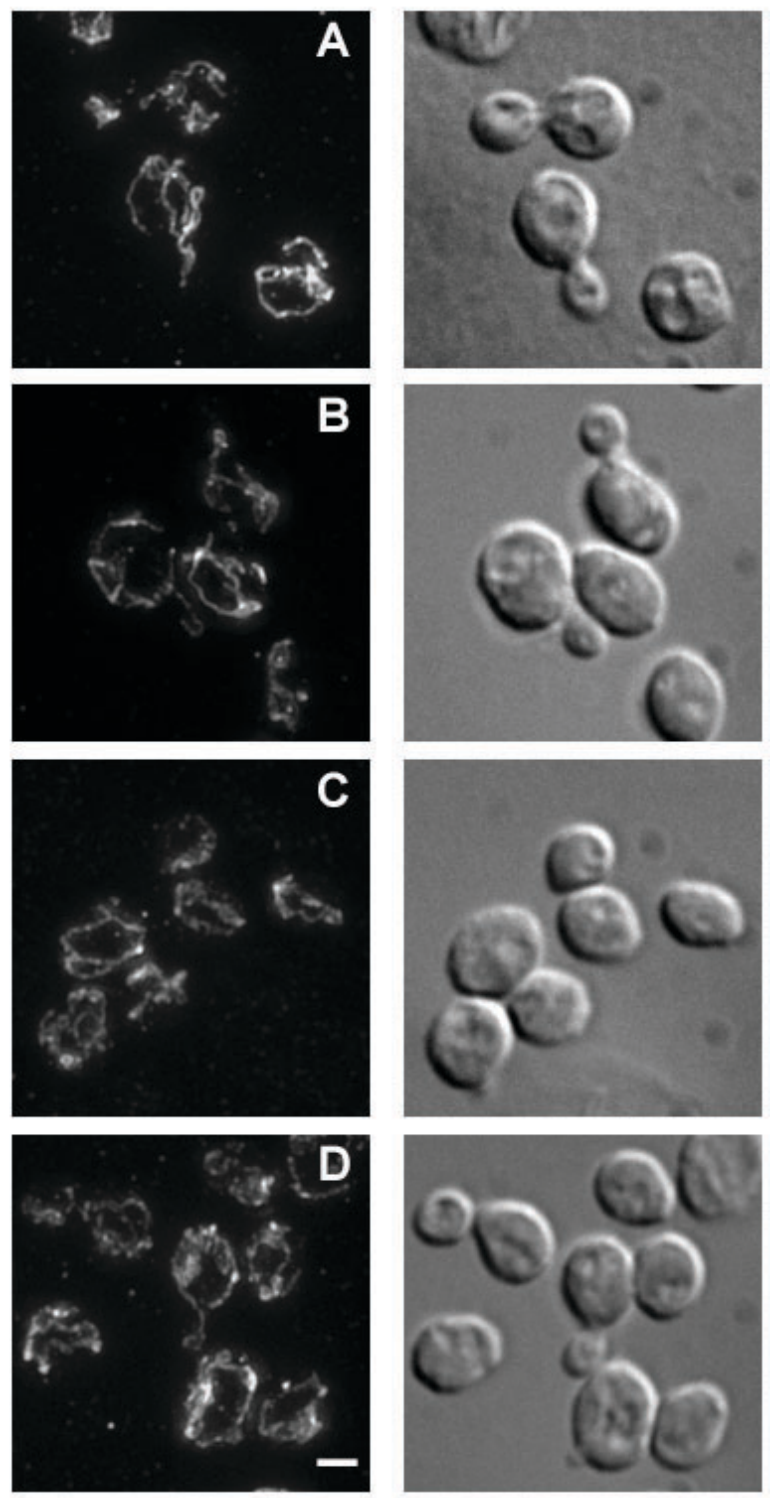

Figure 3. Representative micrographs of $\mathrm{rho}^{+}$ yeast cells visualizing mitochondrial architecture.

Fixed cells were stained with antibody directed against yeast mitochondrial outer membrane porin and examined by fluorescence deconvolution microscopy as in Materials and Methods. The cells on the left are fluorescent images taken at $0.1 \mu \mathrm{m}$ slice thickness. The $16-20$ slices were deconvolved using a nearest-neighbors algorithm and an image created using a maximum intensity projection. The cells on the right are the corresponding brightfield projection images taken at $0.1 \mu \mathrm{m}$ slice thickness (3-4 slices/image) using Nomarski optics. The four strains shown are: (A) YPK9, (B) YPK9 phb1 $\Delta$, (C) YPK9 ras $2 \Delta$, and (D) YPK9 phb1 $\Delta$ ras $2 \Delta$. The characteristic tubular mitochondrial morphology can be readily seen in the mother and daughter cells of all the strains. Bar $=2.5 \mu \mathrm{m}$.
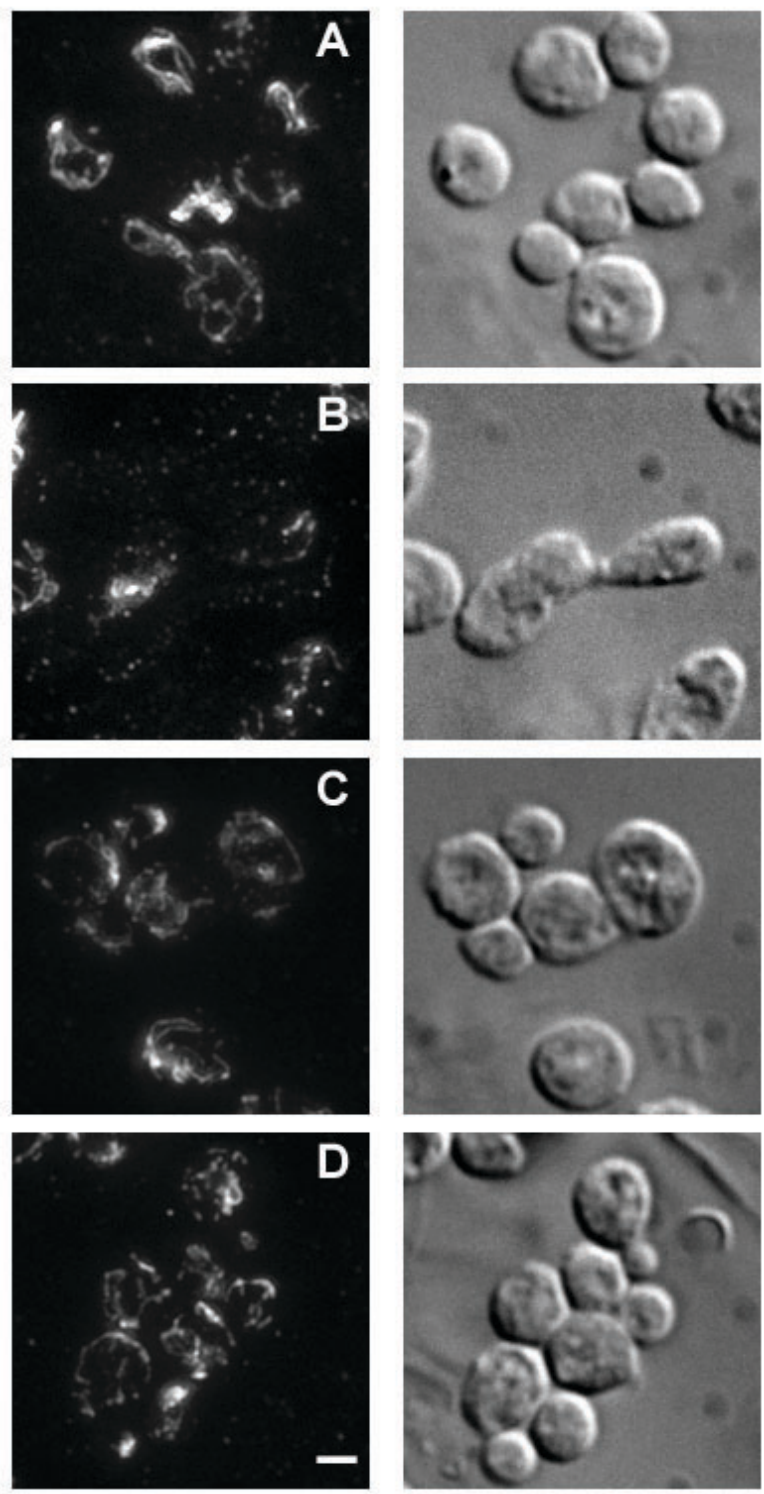

Figure 4. Representative micrographs of rho ${ }^{0}$ yeast cells visualizing mitochondrial architecture.

Cells were treated and displayed as in Fig. 1. The four strains are: (A) YSK365 $\left[r h o^{0}\right]$, (B) YSK365 [rho $\left.{ }^{0}\right]$ phb1 1 , (C) YSK365 [rho ${ }^{0}$ ras2 $\Delta$, and (D) YSK365 $\left[\mathrm{rho}^{0}\right]$ phb1 $\Delta$ ras $2 \Delta$. In the petite strains the tubular mitochondrial networks are smaller, and there are many more punctuate mitochondria. In the YSK365 $\left[r h o^{0}\right]$ phb1 $\Delta$ mutant the cell morphology is altered; there is more extensive dissolution of the normal tubular mitochondrial morphology, and clumping of the mitochondria is extensive. The deletion of RAS2 in this strain restores normal cell morphology and near normal mitochondrial architecture. Bar $=2.5 \mu \mathrm{m}$. 

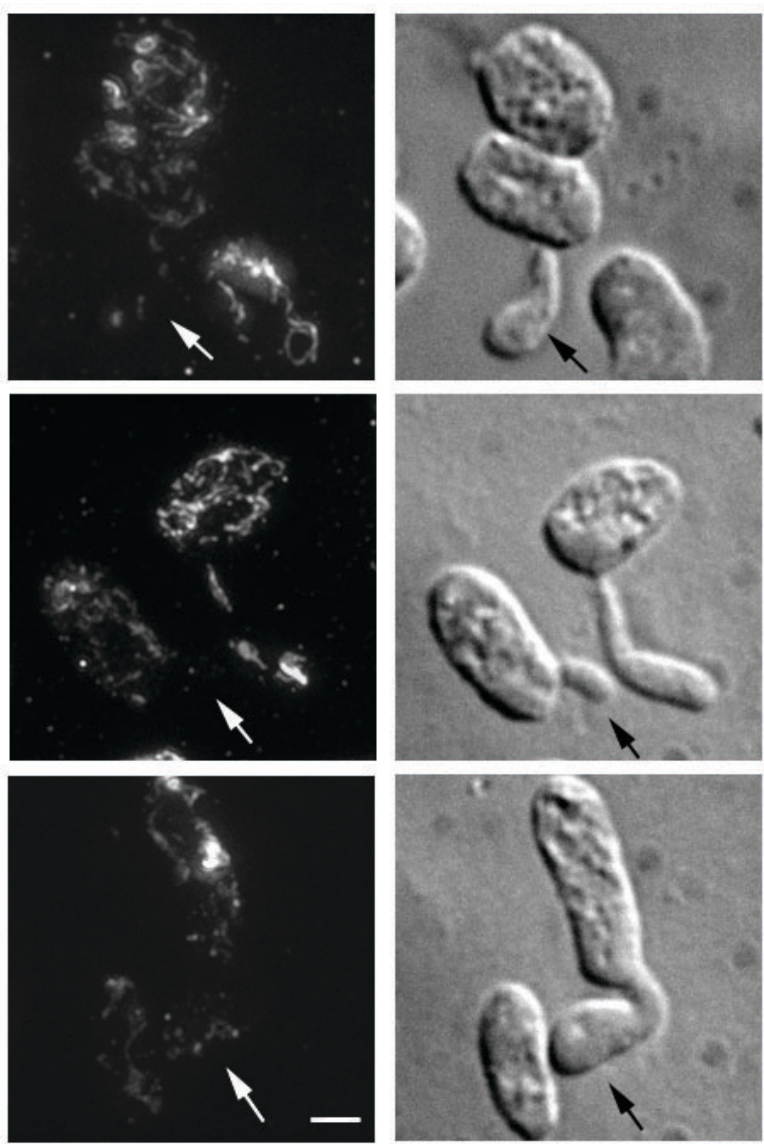

Figure 5. Micrographs of YSK365 $\left[\mathrm{rho}^{0}\right] \mathrm{phb1 \Delta}$ cells showing the variability of cell morphology and mitochondrial architecture and defective mitochondrial inheritance.

Cells were treated and displayed as in Fig. 1. In these cells, there can be seen defective segregation of the mitochondria between mother and daughter. Examples where there is little or no segregation of mitochondria into the daughter cell are indicated by the arrows. Bar $=2.5 \mu \mathrm{m}$.

RAS2, PHB1, and the mitochondrial genome. It indicates that the interplay of these three genetic elements has important functional consequences for the cell that manifest themselves at the level of mitochondrial integrity.

\section{PHB1 deletion increases oxidative stress in dysfunctional mitochondria}

Mitochondria are the major site of production of reactive oxygen species (ROS) in the cell. Petites, in which there is an imbalance in the production of components of the elec- tron transport chain, are likely to generate more oxidative stress. We examined the effect of $P H B 1$ deletion on ROS production in $r h o^{0}$ cells (Fig. 6). In the $r h o^{0}$ phb1 $\Delta$ strain, there was a subset of cells that showed bright fluorescence due to oxidation of the fluorophore (Fig. 6F), and this fluorescence co-localized with the mitochondria visualized with a dye specific to this organelle (Fig. 7). As before (Fig. 4), the deletion of PHB1 in the petites resulted in a loss of mitochondrial integrity in cells, marked by the appearance of spherical aggregates of mitochondrial material. The remaining $r h o^{+}$and $r h o^{0}$ strains showed only faint, non-localized fluorescence due to ROS production (Fig. 6). The frequency of $r h o^{0}$ phb1 $\Delta$ cells with mitochondria producing elevated levels of ROS was relatively low at steady state in culture, but when integrated over several cell divisions (generations) it coincided roughly with the fraction of the cell population that died early in the life span of this strain (Fig. 1B). As expected, the deletion of RAS2 suppressed the effect of the deletion of $P H B 1$ on ROS production in $r h o^{0}$ cells (Fig. 6H). Thus, the imbalance in the electron transport chain caused by elimination of the mitochondrial genome is exacerbated by the lack of prohibitin. However, this metabolic duress is largely counterbalanced by removal of Ras $2 p$ and/or the pathways this protein potentiates.

\section{DISCUSSION}

We have shown that the absence of either or both of the genes PHB1 and PHB2 results in a curtailment of life span in $r h o^{O}$ but not in $\mathrm{rho}^{+}$yeasts and that deletion of the RAS2 gene completely suppresses this longevity phenotype, restoring the life span characteristic of a $\mathrm{rho}^{+}$ras $2 \Delta$ strain with intact prohibitin genes (Fig. 1). Transcripts of $P H B 1 / 2$ gradually decline during the replicative life span, reaching nearly 5-fold lower levels by the median life span in a wild-type strain (Fig. 

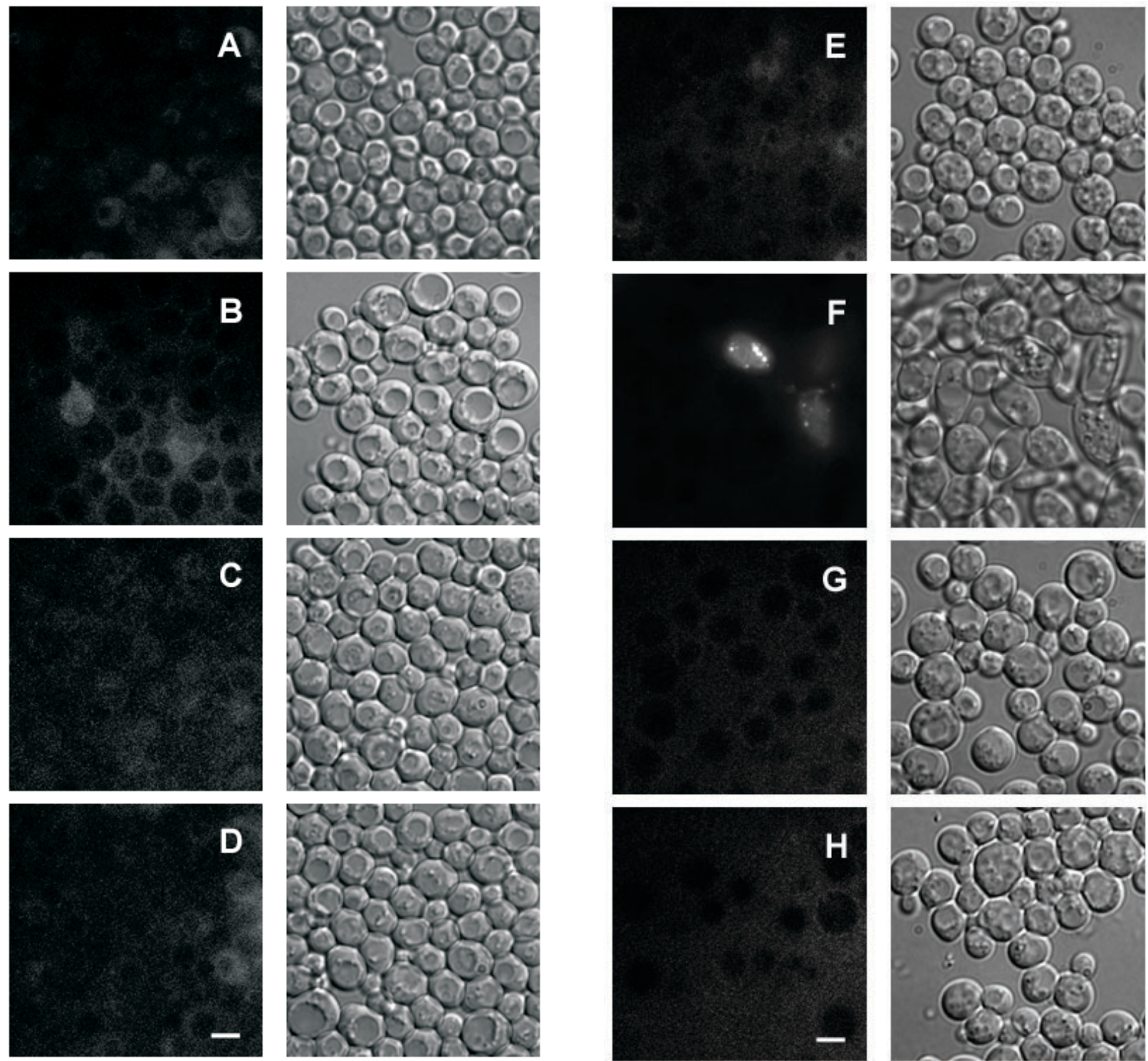

Figure 6. Representative fluorescence micrographs of viable yeast cells incubated with the non-fluorescent dye $\mathrm{H}_{2}$ DCFDA to detect reactive oxygen species.

The dye becomes fluorescent upon oxidation inside the cell (left hand panels). Cells were treated and displayed as in Materials and Methods. Under the conditions used in these experiments, specific fluorescence was only seen in a subset of the YSK365 $\left[\mathrm{rho}^{0}\right]$ phb1 $\Delta$ cells (panel F). The cells on the right are the corresponding Nomarski images. The eight cell strains shown are: (A) YPK9, (B) YPK9 phb1 $\Delta$, (C) YPK9 ras2 $\Delta$, (D) YPK9 phb1 $\Delta$ ras2 $\Delta$, (E) YSK365 $\left[r h o^{0}\right]$, (F) YSK365 $\left[r h o^{0}\right]$ phb1 $\Delta,(\mathrm{G})$ YSK365 $\left[r h o^{0}\right]$ ras $2 \Delta$, and (H) YSK365 $\left[r h o{ }^{0}\right]$ phb1 $\Delta$ ras $2 \Delta$. Bar $=5.0 \mu \mathrm{m}$.

2). The effect of deletion of $P H B 1$ on life span is paralleled by a change in mitochondrial morphology, distribution, and segregation in petites, which is in turn suppressed by deletion of RAS2 (Figs. 3-5). A fraction of the affected cells exhibits elevated intracellular levels of ROS localized to mitochondria in the ab- sence of $P H B 1$, a phenotype which is also suppressed by deletion of RAS2 (Figs. 6 and 7). The defective mitochondrial integrity that leads to improper inheritance of the organelle described here may be the cause of the shortened life span exhibited by petite cells lacking prohibitins, because the defects quantita- 


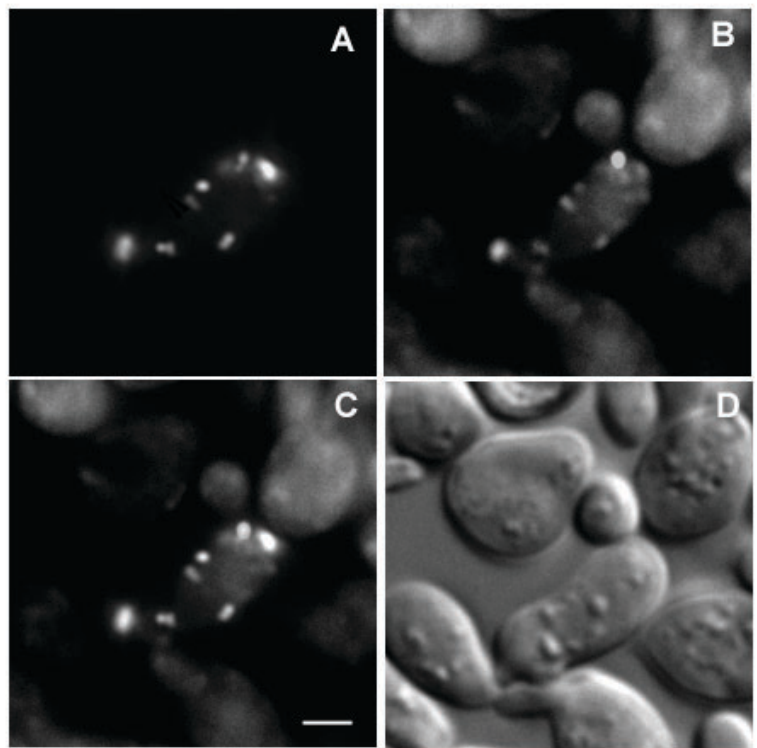

Figure 7. Representative fluorescence micrographs of viable YSK365 $\left[\mathrm{rho}^{\circ}\right]$ phb1 $\mathrm{D}$ cells visualizing active mitochondria and oxidants.

Cells were incubated with $\mathrm{H}_{2}$ DCFDA together with Mitotracker Red CMXRos and visualized as described in Materials and Methods. (A) Micrograph taken with the fluorescein isothiocyanate (FITC) filter set showing a single cell in which the dihydrofluorescein dye has become fluorescent due to oxidation of the fluorophore. (B) Micrograph taken with the Texas Red filter set showing staining of the active mitochondria in the cell. (C) Micrograph taken with both filter sets showing co-localization of the fluorescence, which indicates that oxidation of the fluorophore likely occurs in the defective mitochondria in this cell. (D) The same field taken using Nomarski optics. Bar $=2.5 \mu \mathrm{m}$.

tively approximate the fraction of the cells that die early in the life span and because RAS2 deletion simultaneously suppresses both the life span and the mitochondrial deficit.

Previous studies have shown a decreased life span of $r h o^{+}$cells deleted of PHB1 and/or PHB2 (Coates et al., 1997; Berger \& Yaffe, 1998; Piper et al., 2002). However, the decreases observed were often modest and not always statistically significant. In fact, the statistics were not presented in all cases. Furthermore, the expectation that deletion of either of the two genes should result in curtailment of life span, which is similar in magni- tude and less than or equal to that observed when both genes are deleted, was not consistently observed. Thus, comparisons are not easily entered into. In our study, there was clearly no effect of prohibitin deletions in $r h o^{+}$cells. This is likely to be due to strain and culture condition differences. A comparison with the results of Berger and Yaffe (1998) may be the most illuminating. These investigators observed a decrease in life span in their $r h o^{-}$strain as compared to the coisogenic $r h o^{+}$strain, which contrasts with the increase we observed (Fig. 1). Such strain differences have been reported earlier (Kirchman et al., 1999). Mitochondrial defects or dysfunction induce the retrograde response in yeast. The retrograde response compensates for mitochondrial dysfunction, and when induced maintains or extends life span (Kirchman et al., 1999). The extent of the induction of the retrograde response and the attendant life extension are commensurate, and they increase in proportion to the severity of the mitochondrial deficits (Jazwinski, 2000). One possibility is that in our strain YPK9, in which the retrograde response can be induced on medium containing glucose in contrast to many other strains (Kirchman et al., 1999), the deletion of the prohibitin genes induces this response. This might compensate for the loss of prohibitin. Indeed, there appears to be a small induction of the retrograde response in YPK9 on deletion of PHB1 (not shown). In other strains, a non-repressive carbon source such as raffinose is needed to uncover the induction of the retrograde response (Kirchman et al., 1999). Of course, the implication is that the mitochondrial deficit observed in a $r h o^{+}$ strain carrying prohibitin gene deletions is relatively mild. This indeed would appear to be the case, judging by the minimal effects of prohibitin gene deletions in $r h o^{+}$strains observed by others.

Earlier studies have reported a decrease in life span of $r o^{-}$cells on deletion of PHB1 and PHB2 or on deletion of PHB2 alone 
(Berger \& Yaffe, 1998), consistent with but not as extensive as that demonstrated here. The results presented by Piper et al. (2002) involved a nuclear petite and an inhibitor of respiration, which generates a phenocopy of a petite, but the data shown are not convincing and not statistically significant. In the current study, we show a clear cut decrease in life span (Fig. 1). In contrast to the work of Berger and Yaffe (1998), we find a consistent effect of both the deletion of PHB1 and of PHB2 in $r h o^{0}$ cells, which is augmented when suggested in studies of the effect of the prohibitins on survival in stationary phase (Piper \& Bringloe, 2002).

Our analysis of the effects of $P H B 1$ deletion on mitochondrial integrity (Figs. 3-5) is consistent with that of Berger and Yaffe (1998). Our results, however, show further that the mitochondrial defects can result in inappropriate segregation of mitochondria between the mother and daughter cell, which can readily explain the negative effects of prohibitin loss on bud production and hence
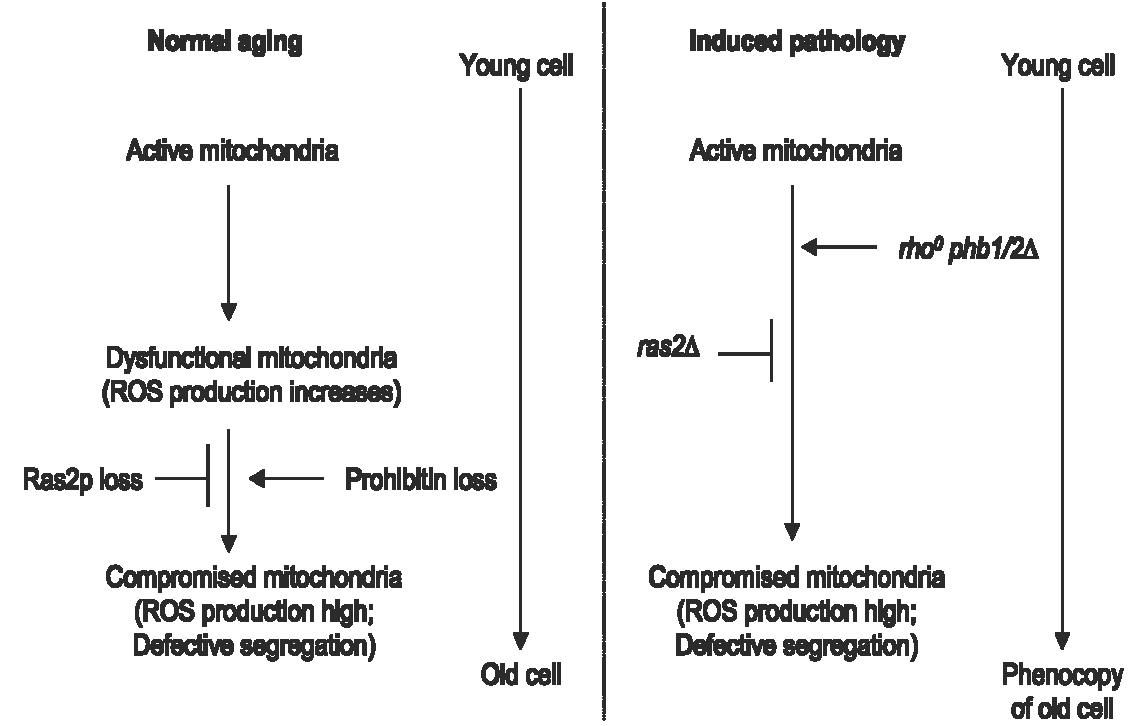

Figure 8. Model for the interaction of prohibitins and Ras2p in yeast aging.

On the left, the sequence of events that occurs during the yeast life span is depicted with its consequences for mitochondrial function, which is postulated to be a limiting factor in yeast longevity. Ras2p augments mitochondrial activity through potentiation of mitochondrial biogenesis period Phb1p and Phb2p are permissive for this effect by facilitating the elimination of imbalances in mitochondrial protein production. Expression of $R A S 2$ and $P H B 1 / 2$ declines coordinately during the life span, keeping this functional relationship between the genes intact. However, the reduction in mitochondrial biogenesis may contribute to the aging process. Overexpression of $R A S 2$ extends life span, but excessive overexpression reverses the effect (Chen et al., 1990; Sun et al., 1994). This may be the result of the lack of sufficient Phb1p and Phb2p to prevent the imbalances described above, as expression of these proteins recedes with age. On the right, the induced pathology caused by deletion of prohibitin genes and its suppression by deletion of RAS2 is shown. This pathology results in a phenocopy of an old yeast cell possessing compromised mitochondria. For further discussion see text.

both genes are deleted. As mentioned earlier, it is not clear why the deletion of both genes has a quantitatively larger effect than the deletion of either gene alone, given the interdependence of the expression of the two prohibitins (Berger \& Yaffe, 1998). The results indicate some additional non-overlapping functions for these proteins, which were also on yeast longevity. Interestingly, Berger and Yaffe (1998) did not observe an effect of a cox4 (nuclear petite) mutation on mitochondrial morphology in cells lacking prohibitins. If the alterations in mitochondrial integrity are taken as the cause of the decrease in life span on deletion of the prohibitin genes, this result would not be consistent with the pur- 
ported effects of prohibitin gene loss on life span in cox4 strains (Piper et al., 2002). The fact that mitochondrial integrity did not suffer in $r^{+} o^{+}$strains on deletion of PHB1 and/or PHB2 yet curtailment of life span occurred (Berger \& Yaffe, 1998) might suggest that the observed changes in mitochondria are not the cause of life shortening. It is also not immediately possible to equate the changes in mitochondrial morphology that have been seen in older $r h o^{+}$cells in which the prohibitin genes were deleted with curtailed life span (Piper et al., 2002). This is due to the lack of a quantitative assessment of cells of several different replicative ages and a comparison with the respective mortality rates. An apparent large fraction of cells incapable of further division in the preparations of older cells would indicate recovery in the preparations of cells that had lingered for some time after cessation of division, with the possibility of post mortem changes. Perhaps, the mitochondrial changes that cause curtailed life span are more subtle, and they only become exacerbated and more easily observed under appropriate conditions after events have run their course (Figs. 4 and 5).

What might the subtle changes in mitochondria be that affect longevity? We have found that a fraction of the rho ${ }^{O}$ phb1 $\Delta$ cells exhibited heightened oxidative stress (Fig. 6). This fraction corresponds in quantity to the fraction of the cells that die early during the life span (Fig. 1). One possibility is that the oxidative stress results in the overt changes in mitochondrial integrity, which in turn limit life span. There is, however, another alternative. Perhaps it is oxidative damage to mitochondria that is incompatible with further cell division (life span) once it has crossed a certain threshold, and the dramatic alterations observed in the mitochondria (Figs. 4 and 5) are a consequence of further oxidative stress, which follows only after the critical life span-limiting events have already taken place. The bimodal survival curves we have observed (Fig. 1) are consis- tent with this interpretation. The oxidative damage is likely to be stochastic. However, such damage to mitochondria would accelerate the generation of ROS in cells that had sustained sufficient damage, resulting in the stratification of the cell population with the emergence of a group of cells suffering early demise. This scenario closely follows the mathematical model of aging based on change as the cause of aging (Jazwinski et al., 1998). Thus in this scenario, it would be damaged/dysfunctional mitochondria that limit life span, regardless of the presence of overt morphologic manifestations.

Dysfunctional mitochondria accumulate in yeast during normal aging, as measured by the loss of mitochondrial membrane potential $\left(\Delta \Psi_{\mathrm{m}}\right)$ with age (Lai et al., 2002). Loss of $\Delta \Psi_{\mathrm{m}}$ would hinder the import of many mitochondrial proteins which are dependent on $\Delta \Psi_{\mathrm{m}}$, creating an imbalance in the mitochondrial proteome. Mitochondrial dysfunction, which can occur in $r h o^{-10}$ cells, results in the induction of the compensatory retrograde response, and this extends yeast longevity (Kirchman et al., 1999). Among the genes that are induced in this response are the prohibitin genes (Traven et al., 2001). Given the apparent function of the prohibitin complex in the protection of the mitochondrion from imbalances in the assembly of inner membrane proteins (Steglich et al., 1999; Nijtmans et al., 2000), Phb1p and Phb2p may play a key role in the retrograde response by providing this protection and thus permitting the life extension obtained. We have recently found that in fact the retrograde response is progressively induced as yeast cells age (Borghouts et al., 2004). This induction titrates mitochondrial dysfunction (Jazwinski, 2000). Thus, deletion of PHB1 and/or PHB2 could have an increasingly deleterious effect on survival as yeast cells age, and this could readily explain the mitochondrial abnormalities observed in older yeast cells (Piper et al., 2002) and the exacerbation of this effect in $r o^{0}$ (Figs. 4 and 5) or $r o^{-}$ cells (Berger \& Yaffe, 1998). 
This view makes mitochondrial dysfunction the primary event, which is enhanced by the loss of prohibitin expression, rather than the loss of prohibitin expression being the primary cause of mitochondrial dysfunction. After all, there is no discernible phenotype of prohibitin loss in cells with fully functional mitochondria (Figs. 1, 3, and 6). We have shown (Fig. 2) that expression of $P H B 1 / 2$ declines with age, making this an appealing scenario for normal aging. Thus, the experimental combination of $r h O^{0}$ with $P H B 1$ deletion generates a pathology that informs on the events that occur during normal yeast aging. Consistent with this interpretation, we have not been able to detect a loss of $\Delta \Psi_{\mathrm{m}}$ in an exponential culture of $r h o^{0}$ phb1 $\Delta$ cells by flow cytometry (not shown). Of course, any such loss may be subtle and affect only a fraction of the cell population. The model shown in Fig. 8 summarizes the interdependence of mitochondrial dysfunction and prohibitin function in yeast longevity. In this model, we propose that the prohibitin complex is not simply a chaperone for holding mitochondrial membrane proteins during the assembly of protein complexes, nor is it just a negative regulator of the m-AAA protease. More, the prohibitin complex functions to deliver supernumerary proteins to this protease for degradation.

We are left with the suppression of the prohibitin loss by the deletion of $R A S 2$ (Figs. 1, 4, and 6). If the loss of prohibitin function under conditions of mitochondrial protein production imbalance is taken into consideration, then it is reasonable to conclude that loss of Ras2 $p$ function might set this balance straight. Ras2 $p$ plays an important role in mitochondrial biogenesis by stimulating the production of the respiratory component of the mitochondrial proteome (Dejean et al., 2002). This is precisely the mitochondrial constituent whose imbalance is under the surveillance of the prohibitin complex. Thus, reduction of the production of nuclear-encoded components of the electron transport chain by deletion of $R A S 2$ or its re- duced expression would be predicted to suppress the loss of the prohibitin complex in rho ${ }^{0}$ yeast cells and during normal yeast aging (Fig. 8). Similar considerations can be extended to the synthesis of components of the mitochondrial ATP synthase (Mabuchi et al., 2000). Interestingly, this mechanism involving RAS2 may operate during normal aging, as expression of the gene declines with replicative age (Sun et al., 1994). This may allow yeasts to live as long as they do, but the imbalance in the mitochondrial proteome may ultimately become too acute to allow survival. In mammalian cells, the situation may be even more complex, because the prohibitin gene promoters contain functional c-myc binding sequences, and c-myc is a transcription factor that plays an important role in cellular metabolism (Coates et al., 2001). However, it is also possible that the effect of the $R A S 2$ deletion is based on a direct interaction of Ras2p with the prohibitin complex. As mentioned earlier, the prohibitins possess motifs that are characteristic of proteins that bind Ras $2 p$, and Ras protein has been reported to be present in mitochondria in mammalian cells (Rebollo et al., 1999).

The results summarized here point to a central role of the mitochondrion in determining yeast longevity. They indicate that mitochondrial integrity is subject to deterioration during normal aging. This deterioration is counterbalanced to maintain life span, among others by the prohibitins. However, these protective mechanisms ultimately succumb to senescence processes. Damaged or dysfunctional mitochondria are sequestered by mother cells when the mothers are still relatively young. Thus, daughter cells are born young as it were, thanks to this "filtering" mechanism (Lai et al., 2002). The RAS2 gene interacts with the mitochondrial genome and with $P H B 1$ and $P H B 2$ in yeast longevity, an interaction that is also likely to be important in human aging (Bonafé et al., 2002). 


\section{R E F E R E N C E S}

Berger KH, Yaffe MP. (1998) Prohibitin family members interact genetically with mitochondrial inheritance components in Saccharomyces cerevisiae. Mol Cell Biol.; 18: 4043-52.

Bonafé M, Barbi C, Olivieri F, Yashin AKF, Vaupel JW, De Benedictis G, Rose G, Carrieri G, Jazwinski SM, Franceschi C. (2002) An allele of HRAS1 3' variable number of tandem repeats is a frailty allele: Implication for an evolutionarily-conserved pathway involved in longevity. Gene.; 286: $121-6$.

Borghouts C, Benguria A, Wawryn J, Jazwinski SM. (2004) Rtg2 protein links metabolism and genome stability in yeast longevity. Genetics., in press.

Chen JB, Sun J, Jazwinski SM. (1990) Prolongation of the yeast life span by the v-Ha-RAS oncogene. Mol Microbiol.; 4: 2081-6.

Coates PJ, Jamieson DJ, Smart K, Prescott AR, Hall PA. (1997) The prohibitin family of mitochondrial proteins regulate replicative lifespan. Curr Biol.; 7: R607-10.

Coates PJ, Nenutil R, McGregor A, Picksley SM, Crouch DH, Hall PA, Wright EG. (2001) Mammalian prohibitin proteins respond to mitochondrial stress and decrease during cellular senescence. Exp Cell Res.; 265: $262-73$.

Dejean L, Beauvoit B, Bunoust O, Guérin B, Rigoulet M. (2002) Activation of Ras cascade increases the mitochondrial enzyme content of respiratory competent yeast. Biochem Biophys Res Commun.; 293: 1383-8.

Egilmez NK, Jazwinski SM. (1989) Evidence for the involvement of a cytoplasmic senescence factor in the aging of the yeast Saccharomyces cerevisiae. J Bacteriol.; 171: 37-42.

Egilmez NK, Chen JB, Jazwinski SM. (1989) Specific alterations in transcript prevalence during the yeast life span. $J$ Biol Chem.; 264: 14312-7.
Epstein CB, Waddle JA, Hale WT, Dave V, Thornton J, Macatee TL, Garner HR, Butow RA. (2001) Genome-wide responses to mitochondrial dysfunction. Mol Biol Cell.; 12: 297-308.

Hayflick L. (1965) The limited in vitro lifetime of human diploid cell strains. Exp Cell Res.; 37: 614-36.

Ikonen E, Fiedler K, Parton RG, Simons K. (1995) Prohibitin, an antiproliferative protein, is localized to mitochondria. FEBS Lett.; 358: 273-7.

Ito H, Fukuda Y, Murata K, Kimura A. (1983) Transformation of intact yeast cells treated with alkali cations. J Bacteriol.; 153: 163-8.

Jazwinski SM. (1990) An experimental system for the molecular analysis of the aging process: The budding yeast Saccharomyces cerevisiae. J Gerontol Biol Sci.; 45: B68-74.

Jazwinski SM. (1996) Longevity genes and aging. Science.; 273: 54-9.

Jazwinski SM. (1999) Longevity genes and aging: A view provided by a genetic model system. Exp Gerontol.; 34: 1-6.

Jazwinski SM. (2000) Metabolic control and gene dysregulation in yeast aging. Ann NY Acad Sci.; 908: 21-30.

Jazwinski SM. (2002) Growing old: Metabolic control and yeast aging. Annu Rev Microbiol.; 56: 769-92.

Jazwinski SM, Kim S, Lai C-Y, Benguria A. (1998) Epigenetic stratification: The role of individual change in the biological aging process. Exp Gerontol.; 33: 571-80.

Jupe ER, Liu XT, Kiehlbauch JL, McClung JK, Dell'Orco RT. (1996) The 3' untranslated region of prohibitin and cellular immortalization. Exp Cell Res.; 224: 128-35.

Kim S, Kirchman PA, Benguria A, Jazwinski SM. (1999) Experimentation with the yeast model. In Methods in aging research. Yu BP, ed, pp 191-213. CRC Press, Boca Raton.

Kirchman PA, Kim S, Lai C-Y, Jazwinski SM. (1999) Interorganelle signaling is a determinant of longevity in Saccharomyces cerevisiae. Genetics.; 152: 179-90. 
Lai C-Y, Jaruga E, Borghouts C, Jazwinski SM. (2002) A mutation in the ATP2 gene abrogates the age asymmetry between mother and daughter cells of the yeast Saccharomyces cerevisiae. Genetics.; 162: $73-87$.

Lumpkin CK, McClung JK, Pereira-Smith OM, Smith JR. (1986) Existence of high abundance antiproliferative mRNA's in senescent human diploid fibroblasts. Science.; 232: $393-5$.

Mabuchi T, Ichimura Y, Takeda M, Douglas MG. (2000) ASC1/RAS2 suppresses the growth defect on glycerol caused by the atp1-2 mutation in the yeast Saccharomyces cerevisiae. J Biol Chem.; 275: 10492-7.

McClung JK, Danner DB, Stewart DA, Smith JR, Schneider EL, Lumpkin CK, Dell'Orco RT, Nuell MJ. (1989) Isolation of a cDNA that hybrid selects antiproliferative mRNA from rat liver. Biochem Biophys Res Commun.; 164: 1316-22.

McClung JK, King RL, Walker LS, Danner DB, Nuell MJ, Stewart CA, Dell'Orco RT (1992) Expression of prohibitin, an antiproliferative protein. Exp Gerontol.; 27: 413-7.

Nijtmans LGJ, de Jong L, Artal Sanz M, Coates PJ, Berden JA, Back JW, Muijsers AO, van der Spek H, Grivell LA. (2000) Prohibitins, act as a membrane-bound chaperone for the stabilization of mitochondrial proteins. EMBO J.; 19: 2444-51.

Nuell MJ, Stewart DA, Walker L, Friedman V, Wood CM, Owens GA, Smith JR, Schneider EL, Dell'Orco R, Lumpkin CK, Danner DB, McClung JK. (1991) Prohibitin an evolutionarily conserved intracellular protein that blocks DNA synthesis in normal fibroblasts and HeLa cells. Mol Cell Biol.; 11: $1372-81$.

Piper PW, Bringloe D. (2002) Loss of prohibitins though it shortens the replicative life span of yeast cells undergoing division, does not shorten the chronological life span of $\mathrm{G}_{0}$-arrested cells. Mech Ageing Dev.; 123: 287-95.

Piper PW, Jones GW, Bringloe D, Harris N, MacLean M, Mollapour M. (2002) The shortened replicative life span of prohibitin mu- tants of yeast appears to be due to defective mitochondrial segregation in old mother cells. Aging Cell.; 1: 149-57.

Rebollo A, Perez-Sala D, Martinez-A C. (1999) Bcl-2 differentially targets $\mathrm{K}$-, N-, and H-Ras to mitochondria in IL-2 supplemented or deprived cells: Implications in prevention of apoptosis. Oncogene.; 18: 4930-9.

Sato T, Saito H, Swensen J, Olifant A, Wood C, Danner D, Sakamoto T, Takita K, Kasumi F, Miki Y, Skolnick M, Nakamura Y. (1992) The human prohibitin gene located on chromosome $17 q 21$ is mutated in sporadic breast cancer. Cancer Res.; 52: 1643-6.

Shama S, Kirchman PA, Jiang JC, Jazwinski SM. (1998) Role of $R A S 2$ in recovery from chronic stress: Effect on yeast life span. Exp Cell Res.; 245: 368-78.

Sikorski RS, Hieter P. (1989) A system of shuttle vectors and yeast host strains designed for efficient manipulation of DNA in Saccharomyces cerevisiae. Genetics.; 122: 19-27.

Smith JR, Pereira-Smith OM. (1996) Replicative senescence: Implications for in vivo aging and tumor suppression. Science.; 273: 63-7.

Steglich G, Neupert W, Langer T. (1999) Prohibitins regulate membrane protein degradation by the m-AAA protease in mitochondria. Mol Cell Biol.; 19: 3435-42.

Sun J, Kale SP, Childress AM, Pinswasdi C, Jazwinski SM. (1994) Divergent roles of $R A S 1$ and $R A S 2$ in yeast longevity. $J$ Biol Chem.; 269: 18638-45.

Terashima M, Kim K-M, Adachi T, Nielsen PJ, Reth M, Köhler G, Lamers MC. (1994) The IgM antigen receptor of $\mathrm{B}$ lymphocytes is associated with prohibitin and a prohibitin-related protein. EMBO J.; 13: 3782-92.

Traven A, Wong JMS, Xu D, Sopta M, Ingles CJ. (2001) Interorganellar communication: Altered nuclear gene expression profiles in a yeast mitochondrial DNA mutant. $J$ Biol Chem.; 276: 4020-7.

Wang S, Nath N, Adlam M, Chellappan S. (1999) Prohibitin, a potential tumor suppressor, interacts with $\mathrm{RB}$ and regulates $\mathrm{E} 2 \mathrm{~F}$ function. Oncogene.; 18: 3501-10. 